\title{
Progress of the application of passive anti-seismic systems
}

\author{
A. Martelli \\ Faculty of Architecture of the University of Ferrara, Italy
}

\begin{abstract}
Over 10,000 structures have been protected in the world by seismic vibration passive control systems and devices, namely by seismic isolation and energy dissipation systems, shape memory alloy devices and shock transmitter units. Such structures are located mostly in Japan, but they are more or less numerous in about 30 further countries too, in particular in the People's Republic of China, the Russian Federation, the USA and Italy. Everywhere, the number of the aforesaid systems and devices is increasing more and more, although the extent of their use is strongly influenced by earthquake experience and the features of the design rules used. Applications concern both new and existing structures of all kinds: bridges and viaducts, civil and industrial buildings, industrial components and installations (including some high risk plants, such as nuclear reactors, other nuclear facilities and some Liquefied Natural Gas tanks) and cultural heritage (monumental buildings, museums, ceilings of archaeological excavations, museum display cases and single masterpieces). Those to civil buildings already include not only the strategic ones (emergency management centres, hospitals, etc.) and the public ones (schools, churches, commercial centres, hotels, airports, etc.), but also dwelling buildings and even many small private houses. This paper summarizes the progress of the application of the aforesaid systems and devices with respect to the state of the art that was presented by the author at the ERES 2007 International Conference. Particular attention is devoted to Italy and the other leading countries. Further information is provided by other papers.
\end{abstract}

Keywords: passive control of vibrations, seismic isolation, energy dissipation, shape memory alloys, shock transmitters, seismic retrofit, buildings, bridges and viaducts, cultural heritage, liquefied natural gas tanks, nuclear reactors. 


\section{Introduction}

Some successful conferences focussing on the Seismic Vibration Passive Control (SVPC) systems and devices - namely the Seismic Isolation (SI) and Energy Dissipation (ED) systems, Shape Memory Alloy Devices (SMADs) and Shock Transmitter Units (STUs), [1-3] - or where this topic was particularly emphasised, [4], were recently co-organized by the Anti-Seismic Systems International Society (ASSISi), its Territorial Section for the United Europe and Other Western European Countries (UE/WEC), the Italian GLIS Association (GLIS - Isolation and Other Anti-Seismic Design Strategies), Working Group 5 on Seismic Isolation of Structures (TG5) of the European Association for Earthquake Engineering (EAEE) and the Italian Agency for New Technologies, Energy and the Environment (ENEA). In addition, numerous members of the aforesaid associations and agency actively participated in other recent international events that were more generally devoted to seismic issues, such as the "International Disaster and Risk Conference (IDRC) Davos 2008", [5], and the $14^{\text {th }}$ World Conference on Earthquake Engineering (14WCEE), [6]. At the latter, the author of this paper co-organized the Special Sessions on "Spectacular Projects of Passively-Controlled Buildings" and presented the state of the art of the application of the SVPC systems and devices in Europe in both such Special Sessions and those on "Spectacular Projects of Base-Isolated Buildings".
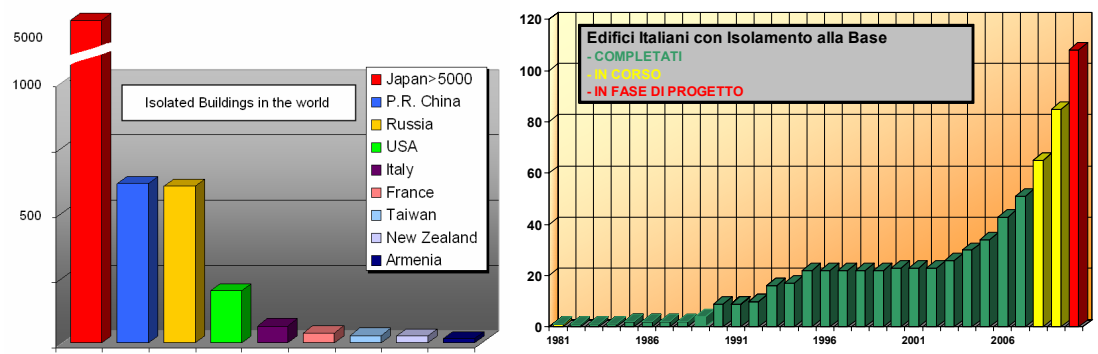

Figure 1: Overall number of building applications of SI in the world in October 2008 (left) and in Italy during years (right).

As witnessed by the proceedings of all above-mentioned conferences and those of further events which recently took place in Italy - like the 2008 annual GLIS Seminar held at Florence on "Applications of Seismic Isolation and Energy Dissipation Systems", [7] - at present there are over 10,000 structures in the world that are protected by means of SVPC systems and devices. Such structures are located mostly in Japan, but they are more or less numerous in about 30 further countries too, in particular in the People's Republic (P.R.) of China, the Russian Federation, the USA and Italy (fig. 1).

Everywhere, the number of such structures is increasing more and more, although the extent of the use of the aforesaid systems and devices is strongly influenced by earthquake experience and the features of the design rules used. 
Applications concern both new and existing structures of all types: bridges and viaducts, civil and industrial buildings, industrial components and installations and cultural heritage.

This paper summarizes the progress of the application of the SVPC systems and devices with respect to the state of the art that was presented by the author at the ERES 2007 International Conference, [8]. Particular attention is devoted to the most recent applications in Italy and in the other leading countries. More details on the use of the SVPC systems and devices in Italy and worldwide may be found, for instance, in the books of Martelli et al [2], Sannino et al [3] and Dolce et al [9], and, as far of cultural heritage is concerned, in the proceedings of the PROHITECH-2009 International Conference to be held in Rome on June 2124, 2009, where special sessions on the application of the SVPC systems and devices have been organized by the author of this paper, [10].

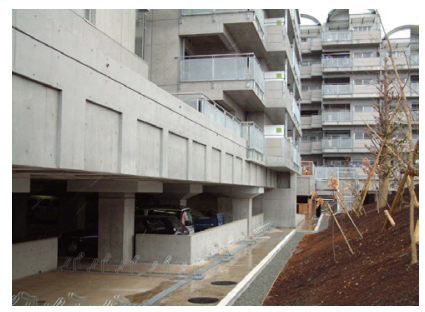

(a)

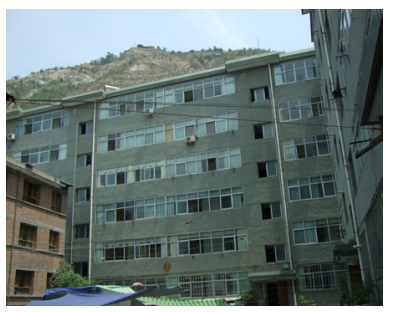

(b)

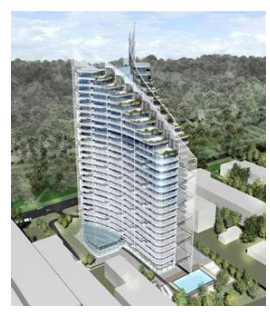

(c)

Figure 2: (a) View of the complex of twenty one 6- to 14-storey buildings, all erected on an unique "artificial ground" slab isolated at Sagamihara (Tokyo area, Japan) with 48 LRBs, 103 SDs and 83 Ball Bearings (BBs) (SI lowered the period of the $111,600 \mathrm{t}$ superstructure to $\mathrm{T}=6.7 \mathrm{~s}$, with a design displacement of 800 $\mathrm{mm}$ ); (b) absence of damage in a seismically isolated Chinese building after the 2008 Wenchuan earthquake; (c) a new seismically isolated Russian hotel complex at Sochi (27 storeys, in addition to 2 underground ones; height $\approx 93 \mathrm{~m}$; total living area $=$ $40,000 \mathrm{~m}^{2}$ ), protected by $156 \mathrm{LRBs}$.

\section{Japan}

Japan, thanks to the availability of an adequate specific code since 2000 and the free adoption of SI since 2001, is more and more consolidating its worldwide leadership on the use of the SVPC systems, with over 5,000 buildings or houses protected by SI (fig. 1) and about 2700 provided with ED systems), [3]. This country, where the first application of base SI dates 1985, is continuing the extensive adoption of the SVPC systems initiated after the excellent behaviour of two isolated buildings near Kobe during the 1995 Hyogo-ken Nanbu earthquake, which was later confirmed for all Japanese isolated buildings struck by subsequent earthquakes, [8]. 
As shown more in detail by a separate paper presented at this Conference, Japanese, on the one hand, have confirmed the trend, initiated some years ago, [8], to isolate even high-rise buildings and sets of buildings supported by a common isolated reinforced concrete (r.c.) structure (the so called "artificial ground", fig. 2a, a solution which enables large savings of construction costs) and, on the other hand, are more and more increasing the number of even very small private houses protected by SI. The latter are already about 3,000, [3]. About 700 Japanese buildings and 2,000 private houses have also been protected by various kinds of dampers: for instance, the applications of the BucklingRestrained Braces (BRBs) were already over 250 in 2003, [3, 8]. These systems too behaved very well during various earthquakes. Moreover, approximately 40 Japanese buildings were seismically controlled by Tuned Mass Dampers (TMDs), of active or hybrid types, in June 2007, and so called "Active Damping Bridges" (ADBs) were recently installed between pairs of adjacent high-rise buildings to reduce the seismic response of both of them, [3].

The use of the SVPC systems also recently increased in Japan for the protection of cultural heritage, [10], and for that of bridges and viaducts. For the latter it began rather later than for buildings; it is being largely based on the use of High Damping Rubber Bearings (HDRBs) and Lead Rubber Bearings (LRBs) and considerably extended especially after the 1995 Hygo-ken Nanbu earthquake (by becoming obligatory for overpasses in Kobe), [8].

Finally, as to the industrial plants, besides detailed studies for the SI (even with three-dimensional - 3D - systems) of various kinds of nuclear reactors, the construction of the Nuclear Fuel Related Facility, supported by 32 Low Damping Rubber Bearings (LDRBs) and LRBs, was completed. Application of SI to large industrial factories also began in 2006: the first, concerning the fabrication of semi-conductors, was built on LRBs and Viscous Dampers (VDs) , [3].

\section{P.R. China}

In the P.R. China very ancient monasteries, temples and bridges, protected by means of rough sliding SI systems, are still standing, which withstood numerous earthquakes, including very violent events (up to 8,2 magnitude, [10]); however, the application of modern SI systems began only in 1991, [8]. In any case, initially the SI systems, then the ED ones too, have rapidly got a footing since that year, so that the isolated buildings were already 490 in June 2005: many of these were to dwelling buildings and no less than 270 to the masonry ones, [8].

At the end of 2006 the number of isolated buildings had increased in the P.R. China to more than 550 and included even rather tall constructions, [3]; furthermore, SI had already been applied to protect 5 further large span structures and 20 road and railway bridges or viaducts, 30 buildings were already protected by ED devices, [3], and 5 buildings and 6 bridges were provided with hybrid or semi-active seismic vibration control systems. Finally, SI had already been used, for the first time in this country, to protect Liquefied Natural Gas (LNG) tanks, [3, 8]. 
In 2007 the P.R. China reached the second place for the number of applications of the SVPC systems in the world, by passing the Russian Federation: in fact, the Chinese isolated buildings resulted to be 610 in May 2007 (against the approximately 600 in the Russian Federation, see later) and those protected by ED systems 45 . The first included the so called "Isolation House Building on Subway Hub", which had been was completed near the centre of Beijing in 2006, and, as mentioned by Martelli [8], consists of fifty 7- to 9storey base-isolated buildings, all separately isolated above an unique huge 2storey isolated structure containing all services and infrastructures, including railways and subways. The objective of this application had been to optimize the use of a wide and valuable central area, which was previously occupied only by railway junctions and the subway, by also minimizing the consequent vibrations and noise: SI enabled a $25 \%$ saving of construction costs, which made it possible to use the available budget for funding an average 3 storey rising of the 50 buildings. In the same years, Chinese application of 3D SI systems to civil buildings and that of isolators or SMADs to cultural heritage had also begun, [3, 10]. At present, the number of isolated Chinese buildings is about 650, [6].

The use of SVPC systems is still rapidly increasing in this country, in spite of the continuing need for submitting the projects to the approval of a special commission. SI is applied not only at the building base or at the top of the lowest floor, but also on more elevated floors (for risings or for erecting highly vertically asymmetric constructions), or at the building top (to sustain, in the case of seismic retrofit, one or more new floors acting as a TMD), or also on structures that join adjacent buildings having different vibrational behaviours.

New applications also include the first sets of buildings on "artificial ground", base and roof SI of stadiums and the protection of valuable objects (e.g. electronic equipment and art objects) by means of SI tables, [3]. Last but not least, it is noted that the excellent behaviour of two r.c. isolated buildings (fig. $2 \mathrm{~b}$ ) and even a 6-storey masonry one during the Wenchuan earthquake of May 12,2008 (in spite of the fact that its violence had been largely underestimated), $[4,5]$, should be a further incentive for an even more rapid extension of the use of SI and other SVPC systems in the P.R. China.

\section{Russian Federation}

The Russian Federation is now third for the number of isolated buildings (around 600 in June 2007). The use of modern SI systems, formed by Rubber Bearings (RBs) of various types, frequently in conjunction with SDs and/or dampers (similar to those adopted in the other countries), is going on replacing that of the previous so called "low cost" isolators (reversed mushroom-shaped r.c. elements), which had been installed since the years 1970s and were not very efficient. After the retrofits of some important historical buildings that have already been mentioned by Martelli [8], recent Russian application includes even high-rise buildings (see Sannino et al [3] and fig. 2c). For some of the latter the installation of SI devices manufactured in Italy is in progress, [3]. 


\section{USA}

In the USA, the application of the SVPC systems is satisfactorily progressing for bridges and viaducts and, with regard to the ED systems, for buildings too. It concerns both new constructions and retrofits. More precisely, HDRBs, LRBs and, more recently ED devices and STUs have already been installed in 600-650 U.S. bridges and viaducts, located in all states, [4], while VDs and Friction Dampers (FDs) already protected approximately 40 and (respectively) 12 buildings in 2001 and BRBs 39 further buildings in 2003, [8].

However, as far as SI of buildings is concerned, the number of new applications still remains limited, in spite of the excellent behaviour of some important US isolated buildings during the 1994 Northridge earthquake and the long experience of application of this technique to such structures (since 1985). As mentioned by Martelli [8], this is a consequence of the uselessly very penalizing design code in force in the USA for the isolated buildings: according to information provided by Erdik et al [1] and Katayama et al [6], the US seismically isolated buildings are now "only" approximately $100 \div 200$, although they are mostly very important and half of them are retrofits.

As already mentioned by Martelli [8], SI of US buildings has been performed using HDRBs, LRBs (in some cases in conjunction with LDRBs, SDs, VDs and other ED devices) and, more recently, the Friction Pendulum System (FPS), as well. With regards to the design earthquake levels adopted in California, we also remind that they correspond very large magnitudes $M$ (e.g. $M=8.3$ for the new 911 Emergency Communications Centre at San Francisco in the years 1990s and $\mathrm{M}=8.0$ for the retrofit of the San Francisco City Hall with 530 LRBs and 62 SDs in 2000): this imposes the use of SI (as the only possibility) for these applications, in spite of its large cost in the USA.

\section{Italy}

The first applications of SVPC systems in Italy date 1975 for bridges and viaducts and 1981 for buildings, namely 4 years before those in Japan and the USA. They concerned the Somplago viaduct of the Udine-Tarviso freeway and, respectively, a suspended steel-structure fire-command building in Naples, [3, 8 , 9]. Thanks to its SI system (formed by SDs on the piles and rubber springs between the deck and the abutments), the Somplago viaduct survived the 1976 Friuli earthquake and (when the deck had already been installed) its second shock without any damage, contrary to most other structures similarly located in the epicentral area; for the Naples building, which had been conventionally designed before the 1980 Campano-Lucano (Irpinia) earthquake (when the site was not yet seismically classified), the insertion of Neoprene Bearings (NBs) at the top (to isolate the suspended structure) and, inside, that of floor dampers and STUs, allowed for not fully modifying the original design.

The excellent behaviour of the Somplago viaduct, in the years of construction of the Italian freeway system, caused an immediate rapid extension of the application of SVPC systems to the new Italian bridges and viaducts. Those 
protected by such systems were already 150 at the beginning of the years 1990s: this ensured the worldwide leadership to Italy for the number and importance of the applications in this field. As to buildings, the development of applications was slower in the first years, but the trend had become very promising, in this field too, at the beginning of the years 1990s, after the erection of the Telecom Italia Centre of Marche Region at Ancona (designed by G.C. Giuliani, GLIS Board and ASSISi member) on 297 HDRBs and the impressive on-site tests performed on one of its 5 buildings (the safety of these, [3, 8, 9], was later certified by the author of this paper).
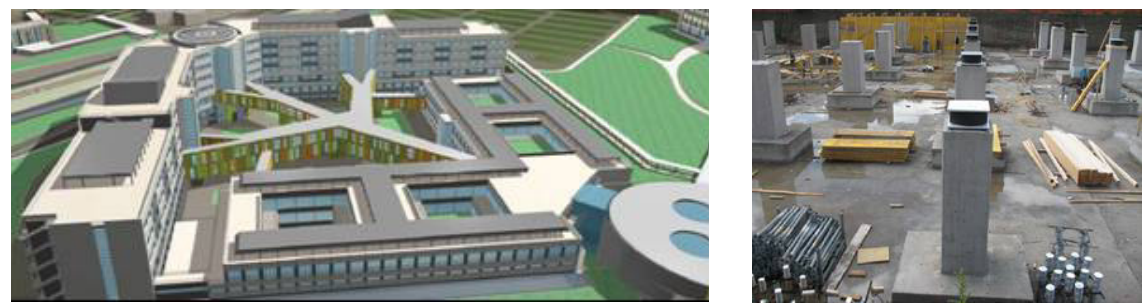

Figure 3: $\quad$ Sketch of the new isolated Del Mare Hospital, during construction at Naples, seismic zone 2, and view of some of some of its 327 HDRBs (most new Italian hospitals being or to be erected in seismic areas now include SI).
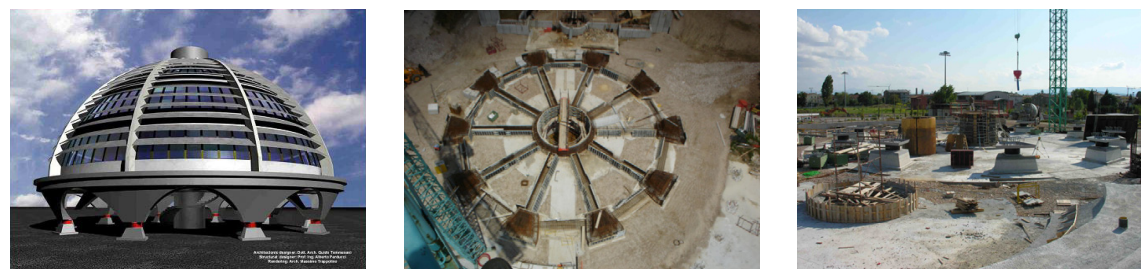

Figure 4: $\quad$ The main building of the Emergency and Management Operative centre (under construction on 10 HDRBs of $1 \mathrm{~m}$ diameter) of the new Civil Defence Centre of Central Italy at Foligno (Perugia). The safety of this and of a second adjacent building, which is also under construction, will be certified by A. Martelli. The Foligno Centre will be formed by 7 isolated buildings, 3 of which have already been completed, [3]. Its site was reclassified from seismic category 2 to seismic zone 1 in 2003, but there was no need for design changes of the structures, thanks to SI, [8].

On the contrary, the use of the SVPC systems became very limited after such a large application (fig. 1): in fact, the Italian Ministry of Constructions, by recognizing that no specific rules for structures provided with the aforesaid systems were included in the Italian seismic code, on the one hand decided that all designs of such structures had to be submitted for approval to a special commission of the Ministry, but, on the other hand, did not make any specific 
design guidelines available until the end of 1998. In addition, such design guidelines, when they were published, resulted to be inadequate and the approval process remained uncertain, very complicated and time consuming. Thus, in spite of its long application tradition, Italy is at present only fifth for the number of isolated buildings already opened to activity: in October 2008 they were about 70 , in addition to several tenths provided with different SVPC systems (19 with ED systems or SMADs and 28 with STUs in May 2007), [3, 8].

Now, however, there is a significant increase of the number of applications completed in the last triennium (the Italian isolated buildings were 25 in June 2005) and, especially, there is a large number of new applications in progress or designed: at least further 20 are nearly completed and numerous have already been or are being designed (see Forni [7] and fig. 1).

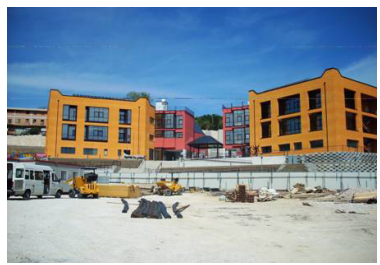

(a)

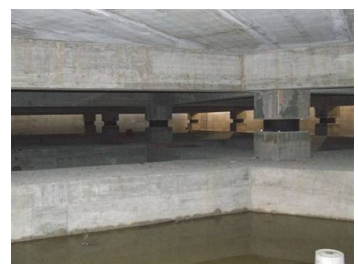

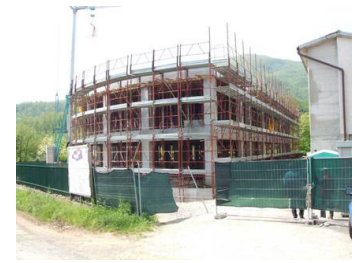

(b)

Figure 5: (a) The two buildings of the new Francesco Jovine school and the "Tre Torri" Polyfunctional Centre, erected at San Giuliano di Puglia, seismic zone 2 since 2003, on an unique isolated slab, and view of its SI system (61 HDRBs and 12 SDs) during construction (the isolators were donated by ALGA, FIP Industriale and TIS, SI design by a team of experts coordinated by ENEA and tests by the University of Basilicata; safety was certified by A. Martelli and C. Pasquale in September 2008); (b) the first new school building at Mulazzo (Massa Carrara), with 14 LRBs and the 15 SDs (one of the 5 schools being reconstructed in Tuscany with SI; safety is being certified by A. Martelli for this school too).

This occurs thanks to the new Italian seismic code, enforced through Ordinance Nr. 3274/2003 of the Prime Minister (mostly as a consequence of the tragedy of San Giuliano di Puglia (Campobasso) during the Molise and Puglia earthquake of October 31, 2002, when the collapse of the former Francesco Jovine primary school killed 27 children, including all the youngest -6 years old - and a teacher). In fact, the new Italian seismic code freed and simplified the adoption of the SVPC systems (in particular SI), by allowing to partially account for the reduction of the seismic forces and quasi-rigid lateral movement of the isolated superstructure when designing it and the foundations, [8]. 


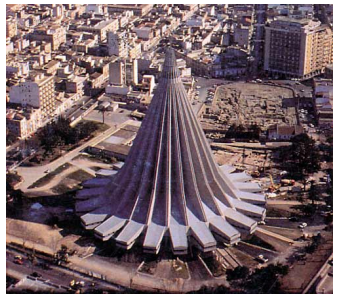

(a)

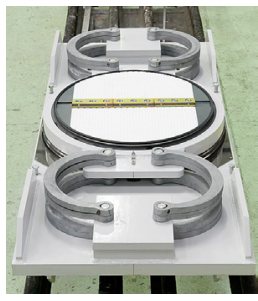

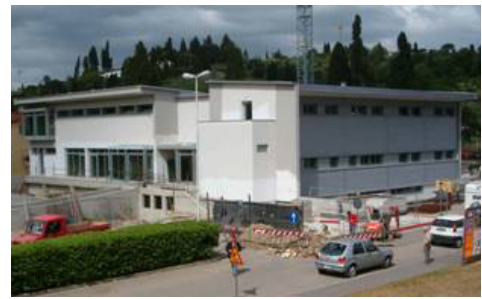

(b)

Figure 6: (a) Sanctuary of "Madonna delle Lacrime" at Syracuse, seismic zone 2 , which may contain up to 11,000 persons, retrofitted by uplifting the dome (22,000 tons) and replacing the previously existing rubber supports by EPDs in 2006; (b) Headquarters of the association "Fratellanza Popolare - Croce d'Oro" at Grassina (Florence), isolated by means of SDs and VDs, a L-shaped building to be used for civil defence (safety was certified by A. Martelli in 2007).

The Italian building applications of SVPC systems (figs. 3-9) concern not only the strategic ones (emergency management centres, hospitals, etc.), the public ones (schools, churches, commercial centres, hotels, airports, etc.) and the industrial ones, but also numerous dwelling buildings (including some private houses) and cultural heritage.

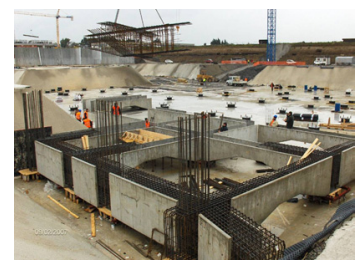

(a)
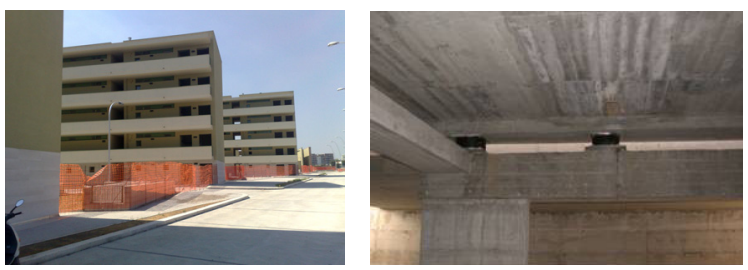

(b)

Figure 7: $\quad$ (a) NATO Centre of South Naples, seismic zone 2 (399 HDRBs and $\sim 20$ dissipative SDs), during construction in 2007; (b) the four r.c. dwelling buildings of the new San Samuele Quarter at Cerignola (Foggia), seismic zone 2, first application of the new Italian seismic code to isolated dwelling buildings, nearly completed with 124 HDRBs (their safety will be certified by A. Martelli in 2009). 

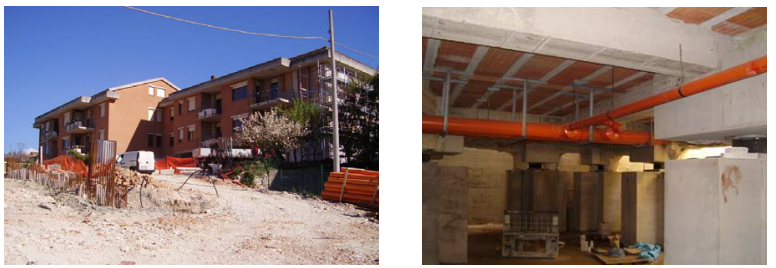

(a)

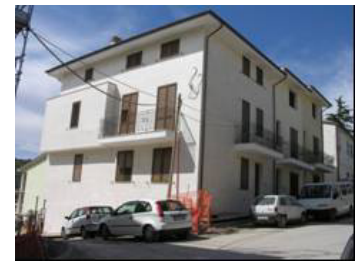

(b)

Figure 8: $\quad$ Figure 8: (a) A r.c. private house at Fabriano (Ancona), seismic zone 2, damaged by the 1997-98 Marche and Umbria earthquake, first EU application of retrofit with SI (56 HDRBs) in a subfoundation (its safety was certified by A. Martelli in 2006); (b) a private house at San Giuliano di Puglia, isolated by 13 HDRBs and 2 SDs (completed in 2007).

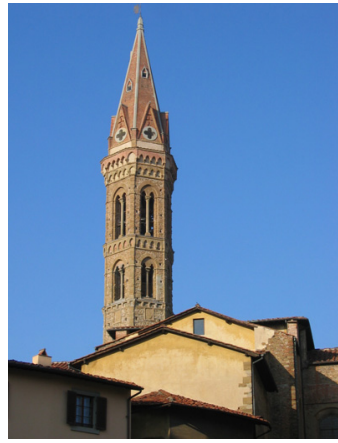

(a)

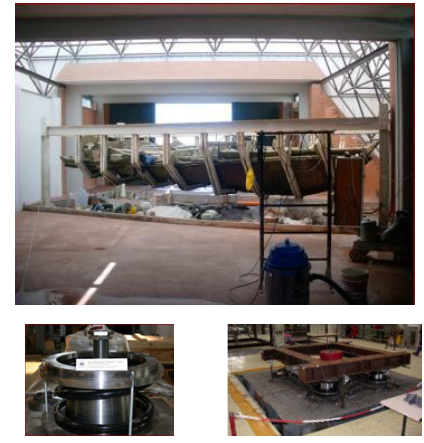

(b)

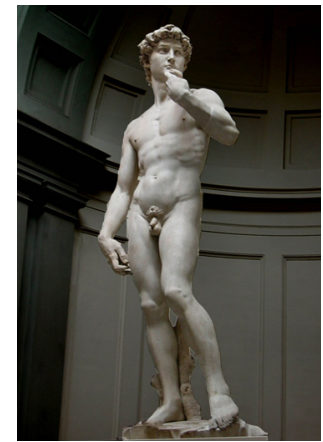

(c)

Figure 9: (a) The bell tower of Badia Fiorentina at Florence, seismically improved with 18 SMADs in series to ties in 2006 (a similar application had been performed in 1999 to the bell tower of the San Giorgio in Trignano Church at San Martino in Rio, Reggio Emilia); (b) the Roman ship of the Ercolano Museum (Naples), recently isolated, with ENEA collaboration, by means of four 3D isolators formed by 3 steel spheres rolling between 2 steel plates and a rubber re-centring cylinder for horizontal SI, with a spring and a VD for the vertical one; (c) David of Michelangelo, for which a SI project has been proposed by the University of Perugia, ENEA and ALGA.

With regard to cultural heritage, the SVPC systems have already been used to protect not only monumental buildings (e.g. the Upper Basilica of St. Francis at Assisi, retrofitted with SMADs and STUs in 1999, after the damages caused by the 1997-98 Marche and Umbria earthquake, the Cathedral of Santa Maria di Collemaggio at L'Aquila, the Badia Fiorentina and the Dome of Siena - see 
Martelli $[3,8,10]$ and fig. 9a), but also some well known single masterpieces, like the Bronzes of Riace, and the Roman ship of the Ercolano Museum (see Martelli $[3,10]$ and fig. 9b). It is hoped that even the David of Michelangelo (fig. $9 \mathrm{c})$ will be protected by a suitable anti-seismic system in the near future, due its high seismic vulnerability owing to its fissured ankles, $[3,10]$.

Finally, it is worthwhile reminding again that Italy remains among the leading countries for the number and importance of bridges and viaducts protected by the SVPC systems and also for the manufacturing of the latter for applications to all kinds of structures abroad.

\section{Other countries}

As to the other countries, Italy is now followed by Taiwan (where the use of SVPC systems began after the 1999 Chi Chi earthquake, thanks to a new favourable seismic code), France, New Zealand, Armenia (as a consequence of the 1988 Spitak earthquake), Turkey (were application began after the 1999 Kocaeli and Duzce events), Mexico, South Korea, Chile, Canada and, in Europe, by Greece (fig. 10a), Portugal, Spain, Cyprus (see separate papers presented at this Conference) and Macedonia (fig. 10b). There the SVPC devices have been frequently manufactured in Italy and some designs are due to Italians, [3, 8].

Italian devices have also been installed in several other countries, like Taiwan, Turkey, South Korea, Venezuela, Indonesia, the USA, Canada, Iran, etc. Further countries that also began using the SVPC systems for the protection of buildings are Argentina, Israel and India. With regard to France, after the first applications to nuclear reactors, spent fuel storage pools and other nuclear structures performed in the years ' $70 \mathrm{~s}$, SI is now being used, in the mainland, for the protection of the Jules Horowitz Reactor and has been planned for that the ITER plant for the controlled fusion; in addition, in the Martinique island, this technique recently became obligatory for schools and other public buildings, [3].

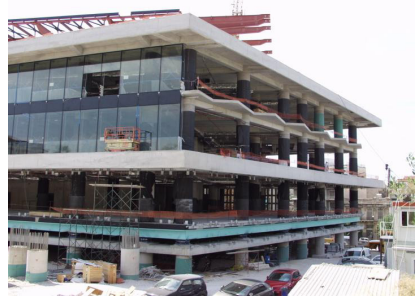

(a)

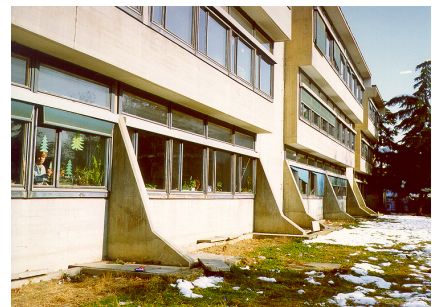

(b)

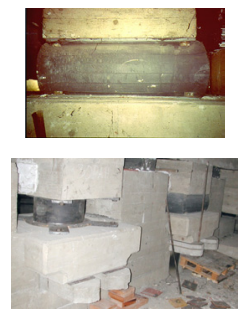

Figure 10: (a) The Acropolis Museum at the Athens Onassis Centre (Greece), isolated by means of 94 German Sliding Isolation Pendulum (SIP) devices in 2006; (b) the seismically isolated Pestalozzi school at Skopje (Macedonia), erected in the years 1960s, one of the recently replaced very degraded LDRBs and view of the new HDRBs during their installation. 


\section{Conclusions}

The SVPC technologies are already widely used in more than 30 countries and their application is increasing more and more, for both new constructions and retrofits, in all fields. The features of the design rules used, as well as earthquake experience, play a key on the success of the aforesaid technologies. Japan is largely the leading country for the number of applications of both SI and ED systems. It is now followed by the P.R. China, the Russian Federation, the USA and Italy. However, Iran should soon get the second place, as soon as the huge project consisting in the SI of hundreds of new dwelling buildings at Parand (a new town under construction near Tehran) will be completed, [6].

Italy (where the contributions provided by ENEA have been of fundamental importance) is the leading country at European level, for the application of both SI and ED. In addition, it is the worldwide leading country as to the use of SVPC systems (in particular SMADs and STUs) to cultural heritage, [10].

SI is now worldwide recognized to be particularly beneficial for the protection of strategic constructions like civil defence centres and hospitals, because its ensures their full integrity and operability after the earthquake, and for public buildings such as schools (and other highly populated structures, like churches, as well), also because the large value of the superstructure period minimizes panic. However, if the code used is adequate, SI has also a great potential for dwelling buildings, because the additional construction costs (if any) are very limited. Hopefully, the use of SVPC systems (in particular, SI) will strongly increase for protecting cultural heritage and high risk plants, as well.

With regard to the latter, SI has a great potential not only for nuclear structures, but also for chemical components like LNG tanks, for which, to date, only very few applications exist (in South Korea, P.R. China, Turkey, France, Greece, and - soon - Mexico [3, 6]): in fact, detailed studies have shown that such systems are indispensable for them in highly seismic areas.

\section{References}

[1] Erdik, M. et al (eds.), Isolation, Energy Dissipation and Active Vibrations Control of Structures - Proceedings of the ASSISi 10th World Conference, May 28-31, 2007, Istanbul, Turkey (DVD), TASI: Istanbul, 2008.

[2] Martelli, A., Sannino, U., Parducci, A. and Braga, F., Moderni Sistemi e Tecnologie Antisismici - Una Guida per il Progettista, ed. R. Irsuti, 21mo Secolo: Milan, 2008 (in Italian).

[3] Sannino, U., Sandi, H., Martelli, A. and Vlad, I., Modern Systems for Mitigation of Seismic Action - Proceedings of the Symposium Held at Bucharest, Romania, on October 31, 2008, AGIR Publishing House: Bucharest, 2009.

[4] Santini, A. and Moraci, N. (eds.), Proceedings of the 2008 Seismic Engineering International Conference Commemorating the 1908 MEssina 
and Reggio Calabria EArthquake (MERCEA'08), American Institute of Physics: Danvers, 1020, 2008.

[5] Martelli, A. and Forni, M., Prevention and mitigation of seismic risk of strategic, public and residential constructions, cultural heritage and industrial plants and components by means of seismic isolation and energy dissipation in Italy and worldwide. IDRC Davos 2008 - Short and Extended Abstracts (DVD), eds. W. Amman et al, Global Risk Forum GRF Davos: Davos Dorf.

[6] Katayama, T., Chen, J. et al (eds.), 14WCEE - Conference Proceedings Oct. 12-17, 2008 - Beijing, China (DVD), CAEE and IAEE: Beijing, 2008.

[7] Forni, M. (ed.), GLIS News, 1-2008, ENEA for GLIS: Bologna, Italy, 2008.

[8] Martelli, A., Seismic isolation and energy dissipation: worldwide application and perspectives. Earthquake Resistant Engineering Structures VI, Proceedings of the Sixth International Conference on Earthquake Resistant Engineering Structures (ERES 2007), Bologna, Italy, ed. C.A. Brebbia, WIT Press: Southampton and Boston, pp. 105-116, 2007.

[9] Dolce, M., Martelli, A. and Panza, G., Moderni Metodi di Protezione dagli Effetti dei Terremoti, Special edition for the Italian Civil Defence Department, ed. A. Martelli, 21mo Secolo: Milan, 2006 (in Italian).

[10] Martelli, A., Development and application of innovative anti-seismic systems for the protection of cultural heritage (Key-note lecture). Proceedings of the First International Conference on Protection of Cultural Heritage (PROHITECH 2009), Rome, Italy, June 21-24, 2009, ed. F. Mazzolani, Taylor and Francis: AK Leiden, to be published in 2009. 